\title{
Hysterectomy in Poland between 2011 and 2016. Changing trends in the surgical approach to hysterectomy
}

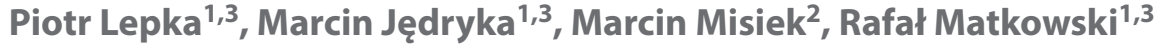 \\ ${ }^{1}$ Division of Surgical Oncology, Gynecological Oncology, Chemotherapy and Department of Oncology, \\ Wroclaw Medical University, Wroclaw, Poland \\ ${ }^{2}$ Department of Gynecologic Oncology, Holycross Cancer Center, Kielce, Poland \\ ${ }^{3}$ Lower Silesian Oncology Center in Wroclaw, Polska
}

\begin{abstract}
Objectives: In Poland, approximately 35,000 women a year undergo hysterectomy. The surgical approach may vary depending on the indications and experience of the operator and advances in laparoscopic surgical techniques. The aim of the present study was to analyze trends in the use of various types of hysterectomy in Poland between 2011 and 2016. Summary values were given as numbers and percentages. Annual incidence of procedures and identify factors which influence these changes in gynecological practice.

Material and methods: Data on hysterectomy procedures performed between 2011 and 2016 in Poland acquired from the National Health Fund reports were extracted and analyzed. Summary values were given as numbers, percentages and rate ratios (RR). Annual incidence of procedures and identify factors that influence these changes in gynecological practice.

Results: Between 2011 and 2016, 215,744 women were treated by hysterectomy in inpatient settings. The total number of those procedures in analyzed period decreased by $11.5 \%$; the incidence rate dropped by 2.15 per 100,000 women. A significant increase in laparoscopic procedures was observed $(R R=3.85 ; \mathrm{Cl}: 3.57-4.16 ; \mathrm{p}<0.001)$ along with a decrease in the number of abdominal operations ( $R R=0.82 ; \mathrm{Cl}: 0.81-0.83 ; \mathrm{p}<0.001)$.

Conclusions: Surgical technique advances, introduction of intrauterine systems and hormonal therapy, as well as recommendations of international institutions have brought about changes in the methods and frequency of hysterectomy. The laparoscopic approach has been gaining popularity since it is beneficial both for patients and public health system. However, the percentage of advanced minimally invasive hysterectomies is still low in Poland in comparison to other countries. Key words: hysterectomy, statistics, laparoscopy, Poland
\end{abstract}

Ginekologia Polska 2018; 89, 10: 529-535

\section{INTRODUCTION}

Hysterectomy is one of the most commonly performed gynecological procedures worldwide. According to the data acquired from the National Health Fund (NHF), approximately 35,000 women a year undergo this procedure. The most frequent indications for hysterectomy apart from neoplastic diseases of the reproductive organs are uterine fibroids, abnormal uterine bleeding, pelvic organ prolapse and endometriosis [1]. Considering the anatomical extent of hysterectomy, the procedures can be divided into total hysterectomy $(\mathrm{TH})$ and supracervical hysterectomy (SH). The surgical approach is chosen based on the indication for hysterectomy and experience of the operator. In the case of total hysterectomy, abdominal or vaginal approach can be applied. Abdominal surgeries can be divided into open and laparoscopic. SH can be carried out using the abdominal approach (laparotomy or laparoscopy).

Over the years, various medical trends influenced the number and type of the performed surgeries in gynecology [2]. Initially, the conservative treatment with a limited role of surgery was popular [3, 4]. Introduction of the embolization 
of the uterine arteries into the treatment of benign tumors of the uterus and other non-operative methods of ablation into the treatment of abnormal uterine bleeding made these methods more common [5]. Similarly, conservative treatment is often chosen in cervical dysplasia. A considerable increase in the use of procedures aimed at sparing the uterus and patient fertility is widely observed [6]. Another aspect is the development of minimally invasive techniques. Almost three decades have passed since the first laparoscopic hysterectomy was carried out but rapid implementation of this surgical method can be observed in many countries $[7,8]$.

Recently, considerable changes in the operative modalities as well as qualification procedures to treatment of gynecological diseases have been observed also in Poland. However, our knowledge on how these trends affected the frequency of the performed hysterectomies is limited. Therefore, we analyzed the reports from the National Health Fund to evaluate the number and type of operations on the female reproductive organ.

\section{Objectives}

The aim of the present study was to analyze trends in the use of various types of hysterectomy in Poland between 2011 and 2016.

\section{MATERIAL AND METHODS}

In the present study, we used National Health Fund (NFZ - Narodowy Fundusz Zdrowia) data because it is the biggest and essentially the only public payer of health services in Poland. Information from the National Health Fund databases is a source of reliable knowledge about medical procedures performed in Poland. National Health Fund performs the analysis of Diagnosis-Related Groups (JGP — Jednorodne Grupy Pacjentów) annually. The summary encompasses the number of surgical procedures performed, primary diagnosis according to the International Statistical Classification of Diseases and Related Health Problems (ICD-10) and medical procedures according to the International Classification of Procedures in Medicine (ICD-9).

Data on the gynecological treatment performed between 2011 and 2016 were collected and analyzed. Special attention was given to the number of performed hysterectomies and to the type of such surgeries. Patients were divided into five groups depending on the type of hysterectomy: total abdominal hysterectomy (TAH), total laparoscopic hysterectomy (TLH), supracervical abdominal hysterectomy $(\mathrm{SAH})$, supracervical laparoscopic hysterectomy (SLH), and vaginal hysterectomy (VH).

The data were statistically analyzed using the R Project for Statistical Computing v. 3.2.2. The analysis encompassed the annual number of the procedures and the population of women in given years in Poland. They were presented as numbers and percentages. The annual incidence of the procedures and the rate ratios (RR) were calculated to enable objective comparison between the procedures.

\section{RESULTS}

Over the study period, 215,744 women were treated with hysterectomy in the inpatient settings. Between 2011 and 2015, a regular decrease in the number of hysterectomies in Poland was observed. In 2015, the number of the procedures was lower by $13.0 \%(n=4898)$ in comparison to 2011. In 2016, an increase by $1.7 \%(n=558)$ was observed in comparison to 2015 . In the entire analyzed period, the total number of hysterectomies dropped by $11.5 \%$ in comparison to reference year, i.e. 2011 (Fig. 1). A decreasing trend is also visible in the analysis of the incidence of hysterectomy per 100,000 women in Poland (Tab. 1).

A significant drop in the number of TAH was observed. It decreased from 24,626 in 2011 to 18,711 in 2016 what is the decrease by $24.0 \%(\mathrm{RR}=0.76 ; \mathrm{Cl}: 0.75-0.78 ; \mathrm{p}<0.001)$. In case of TLH, there is a considerable increase from 62 proce-

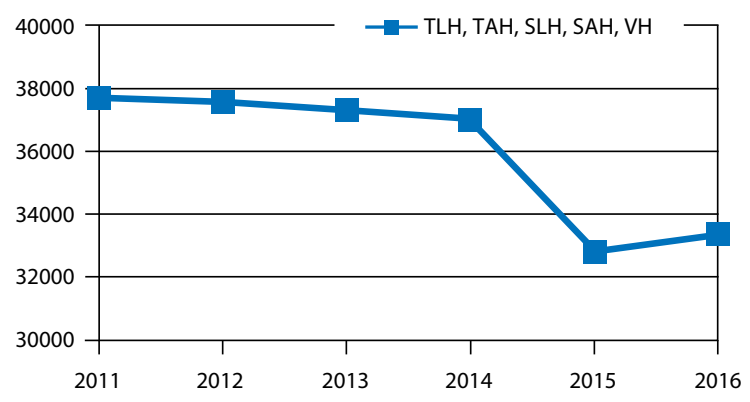

Figure 1. Total number of hysterectomies; $\mathrm{TAH}-$ total abdominal hysterectomy; TLH - total laparoscopic hysterectomy; SAH - supracervical abdominal hysterectomy; SLH - supracervical laparoscopic hysterectomy; $\mathrm{VH}$ - vaginal hysterectomy

\begin{tabular}{|c|c|c|c|c|c|c|}
\hline & 2011 & 2012 & 2013 & 2014 & 2015 & 2016 \\
\hline Total number of women & $19,883,870$ & $19,883,965$ & $19,866,124$ & $19,858,793$ & $19,839,248$ & $19,839,826$ \\
\hline $\begin{array}{l}\text { Total number of all } \\
\text { hysterectomies }\end{array}$ & 37700 & 37547 & 37318 & 37017 & 32802 & 33360 \\
\hline $\begin{array}{l}\text { Incidence rate per } \\
10.000 \text { women }\end{array}$ & 18.96 & 18.88 & 18.78 & 18.64 & 16.53 & 16.81 \\
\hline
\end{tabular}


dures in 2011 to 802 procedures in 2016 what is the increase by $1,193.5 \%(R R=12.96 ; \mathrm{Cl}: 10.01-16.79 ; \mathrm{p}<0.001)$. Those trends are presented in Figure 2 and Table 2.

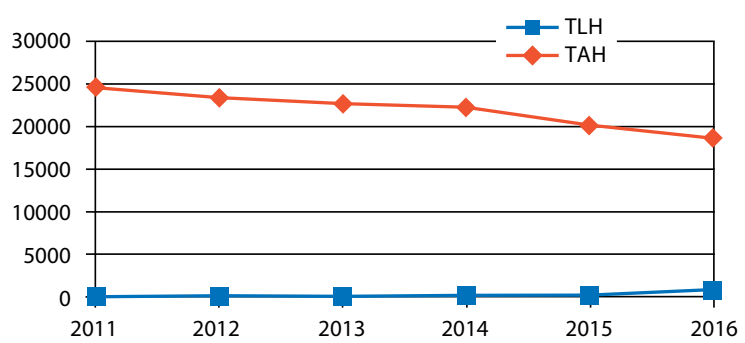

Figure 2. Comparison of the number of total abdominal and laparoscopic hysterectomy procedures; $\mathrm{TAH}$ - total abdominal hysterectomy; TLH — total laparoscopic hysterectomy
Over the study period, $66,285 \mathrm{SAH}$ procedures were performed. After initial increase by $7.1 \%$ from 10,738 in 2011 to 11,501 in 2014 ( $R R=1.07 ; C l: 1.04-1.10 ; p<0.001)$, their number decreased from 11,501 in 2014 to 10,282 in 2016 what is the decrease by $10.6 \%$ (Tab. 3).

In case of SLH, an increasing trend was observed as their number rose from 788 in 2011 to 1,983 in 2014 what is the increase by $151.6 \%(\mathrm{RR}=1.07$; $\mathrm{Cl}: 1.04-$ $1.10 ; p<0.001)$. Annual changes in SLH are presented in Table 3. In 2015, there was the lowest number of SLH performed. Their number dropped from 1,983 in 2014 to 632 in 2015 what is the decrease by $68.1 \%(R R=0.32 ; \mathrm{Cl}$ : $0.29-0.35 ; p<0.001)$. Next, an increase by $262.2 \%$ in the number of SLH procedures was observed. Their number rose from 632 in 2015 to 2289 in $2016(R R=3.62$; Cl:

Table 2. Comparison of the number of total hysterectomy procedures with abdominal and laparoscopic approach. Rate ratio is calculated in relation to 2011 as the reference year

\begin{tabular}{|c|c|c|c|c|c|c|}
\hline & 2011 & 2012 & 2013 & 2014 & 2015 & 2016 \\
\hline Total number of women & $19,883,870$ & $19,883,965$ & $19,866,124$ & $19,858,793$ & $19,839,248$ & $19,839,826$ \\
\hline TAH & 24626 & 23398 & 22744 & 22243 & 20121 & 18711 \\
\hline TLH & 62 & 73 & 35 & 117 & 166 & 802 \\
\hline $\begin{array}{l}\text { TAH incidence } \\
\text { per } 10,000 \text { women }\end{array}$ & 12.38 & 11.77 & 11.45 & 11.20 & 10.14 & 9.43 \\
\hline $\begin{array}{l}\text { TLH incidence } \\
\text { per } 10,000 \text { women }\end{array}$ & 0.03 & 0.04 & 0.02 & 0.06 & 0.08 & 0.40 \\
\hline $\mathrm{TAH}$ rate ratio with $\mathrm{Cl}$ & & $\begin{array}{l}\mathrm{RR}=0.95 \\
\mathrm{Cl}: 0.93-0.97 ; \\
\mathrm{p}<0.001\end{array}$ & $\begin{array}{l}\mathrm{RR}=0.92 \\
\mathrm{Cl}: 0.09- \\
0.09 \\
p<0.001\end{array}$ & $\begin{array}{l}\mathrm{RR}=0.90 \\
\mathrm{Cl}: 0.89-0.92 \\
\mathrm{p}<0.001\end{array}$ & $\begin{array}{l}\mathrm{RR}=0.82 \\
\mathrm{Cl}: 0.80-0.83 \\
\mathrm{p}<0.001\end{array}$ & $\begin{array}{l}\mathrm{RR}=0.76 \\
\mathrm{Cl}: 0.75-0.78 \\
\mathrm{p}<0.001\end{array}$ \\
\hline TLH rate ratio with $\mathrm{Cl}$ & & $\begin{array}{l}R R=1.18 \\
C l: 0.84-1.65 \\
p=0.3438\end{array}$ & $\begin{array}{l}\mathrm{RR}=0.57 \\
\mathrm{Cl}: 0.37- \\
0.86 \\
\mathrm{p}=0.006\end{array}$ & $\begin{array}{l}\mathrm{RR}=1.89 \\
\mathrm{Cl}: 1.39-2.57 \\
p<0.001\end{array}$ & $\begin{array}{l}\mathrm{RR}=2.68 \\
\mathrm{Cl}: 2.00-3.59 \\
\mathrm{p}<0.001\end{array}$ & $\begin{array}{l}\mathrm{RR}=12.93 \\
\mathrm{Cl}: 10.01-16.79 \\
\mathrm{p}<0.001\end{array}$ \\
\hline
\end{tabular}

$\mathrm{TAH}$ - total abdominal hysterectomy; $\mathrm{TLH}$ — total laparoscopic hysterectomy; $\mathrm{Cl}$ - confidence interval; $\mathrm{RR}$ — rate ratio

Table 3. Comparison of the number of supracervical hysterectomy procedures with abdominal and laparoscopic approach. Rate ratio is calculated in relation to 2011 as the reference year

\begin{tabular}{|c|c|c|c|c|c|c|}
\hline & 2011 & 2012 & 2013 & 2014 & 2015 & 2016 \\
\hline Total number of women & $19,883,870$ & $19,883,965$ & $19,866,124$ & $19,858,793$ & $19,839,248$ & $19,839,826$ \\
\hline $\mathrm{SAH}$ & 10738 & 11412 & 11665 & 11501 & 10687 & 10282 \\
\hline SLH & 788 & 1225 & 1582 & 1983 & 632 & 2289 \\
\hline $\begin{array}{l}\text { SAH incidence } \\
\text { per } 10,000 \text { women }\end{array}$ & 5.40 & 5.74 & 5.87 & 5.79 & 5.39 & 5.18 \\
\hline $\begin{array}{l}\text { SLH incidence } \\
\text { per } 10,000 \text { women }\end{array}$ & 0.40 & 0.62 & 0.80 & 1.00 & 0.32 & 1.15 \\
\hline $\mathrm{SAH}$ rate ratio with $\mathrm{Cl}$ & & $\begin{array}{l}\mathrm{RR}=1.06 \\
\mathrm{Cl}: 1.04-1.09 \\
p<0.001\end{array}$ & $\begin{array}{l}\mathrm{RR}=1.09 \\
\mathrm{Cl}: 1.06-1.12 \\
p<0.001\end{array}$ & $\begin{array}{l}\mathrm{RR}=1.07 \\
\mathrm{Cl}: 1.04-1.10 \\
p<0.001\end{array}$ & $\begin{array}{l}\mathrm{RR}=1.00 \\
\mathrm{Cl}: 0.97-1.02 \\
p=0.854\end{array}$ & $\begin{array}{l}R R=0.96 \\
C l: 0.93-0.99 \\
p=0.0028\end{array}$ \\
\hline SLH rate ratio with $\mathrm{Cl}$ & & $\begin{array}{l}\mathrm{RR}=1.55 \\
\mathrm{Cl}: 1.42-1.70 \\
p<0.001\end{array}$ & $\begin{array}{l}\mathrm{RR}=2.01 \\
\mathrm{Cl}: 1.84-2.19 \\
p<0.001\end{array}$ & $\begin{array}{l}\mathrm{RR}=2.51 \\
\mathrm{Cl}: 2.32-2.74 \\
\mathrm{p}<0.001\end{array}$ & $\begin{array}{l}\mathrm{RR}=0.80 \\
\mathrm{Cl}: 0.72-0.89 \\
p<0.001\end{array}$ & $\begin{array}{l}\mathrm{RR}=2.91 \\
\mathrm{Cl}: 2.68-3.16 \\
p<0.001\end{array}$ \\
\hline
\end{tabular}

$\mathrm{SAH}$ — supracervical abdominal hysterectomy; $\mathrm{SLH}$ — supracervical laparoscopic hysterectomy; $\mathrm{Cl}$ — confidence interval; $\mathrm{RR}$ — rate ratio 


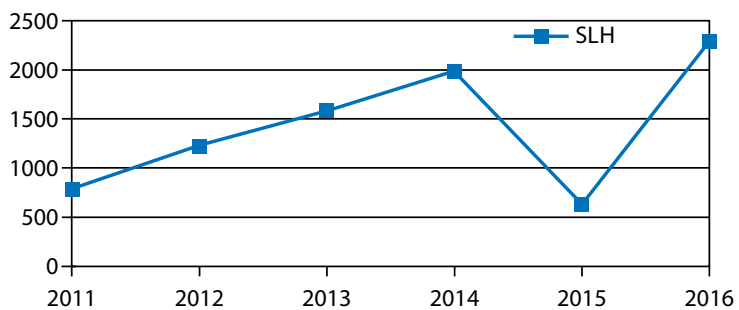

Figure 3. Number of supracervical laparoscopic hysterectomy (SLH) procedures

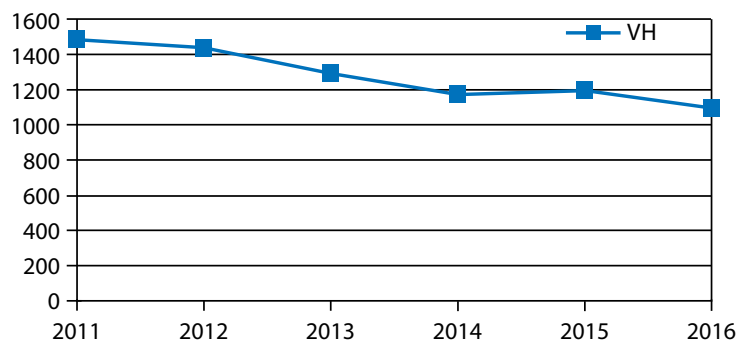

Figure 4. Total number of vaginal hysterectomies (VH)

Table 4. Comparison of the surgical approaches of hysterectomy. Rate ratio for a given year is calculated with a preceding year as the reference year

\begin{tabular}{|c|c|c|c|c|c|c|}
\hline & 2011 & 2012 & 2013 & 2014 & 2015 & 2016 \\
\hline $\begin{array}{l}\text { Total number of } \\
\text { women }\end{array}$ & $19,883,870$ & $19,883,965$ & $19,866,124$ & $19,858,793$ & $19,839,248$ & $19,839,826$ \\
\hline \multirow[t]{2}{*}{ TAH } & 24626 & 23398 & 22744 & 22243 & 20121 & 18711 \\
\hline & & $\begin{array}{l}\mathrm{RR}=0,95 \\
\mathrm{Cl}: 0,93-0.97 \\
\mathrm{p}<0,001\end{array}$ & $\begin{array}{l}\mathrm{RR}=0,97 \\
\mathrm{Cl}: 0,96-0.99 \\
\mathrm{p}=0,0032\end{array}$ & $\begin{array}{l}\mathrm{RR}=0,98 \\
\mathrm{Cl}: 0,96-1,00 \\
\mathrm{p}=0,0202\end{array}$ & $\begin{array}{l}\mathrm{RR}=0,91 \\
\mathrm{Cl}: 0,89-0,92 \\
\mathrm{p}<0,0001\end{array}$ & $\begin{array}{l}\mathrm{RR}=0,93 \\
\mathrm{Cl}: 0,91-0,95 \\
\mathrm{p}<0,0001\end{array}$ \\
\hline \multirow[t]{2}{*}{ TLH } & 62 & 73 & 35 & 117 & 166 & 802 \\
\hline & & $\begin{array}{l}\mathrm{RR}=1,18 \\
\mathrm{Cl}: 0,84-1,65 \\
\mathrm{p}=0,3438\end{array}$ & $\begin{array}{l}\mathrm{RR}=0,48 \\
\mathrm{Cl}: 0,32-0,72 \\
\mathrm{p}<0,0001\end{array}$ & $\begin{array}{l}\mathrm{RR}=3,34 \\
\mathrm{Cl}: 2,29-4,88 \\
\mathrm{p}=0,0003\end{array}$ & $\begin{array}{l}\mathrm{RR}=1,42 \\
\mathrm{Cl}: 1,12-1,80 \\
\mathrm{p}=0,0035\end{array}$ & $\begin{array}{l}\mathrm{RR}=4,83 \\
\mathrm{Cl}: 4.09-5,71 \\
\mathrm{p}<0,0001\end{array}$ \\
\hline \multirow[t]{2}{*}{ SAH } & 10738 & 11412 & 11665 & 11501 & 10687 & 10282 \\
\hline & & $\begin{array}{l}\mathrm{RR}=1,06 \\
\mathrm{Cl}: 1,04-1,09 \\
\mathrm{p}<0,001\end{array}$ & $\begin{array}{l}\mathrm{RR}=1,02 \\
\mathrm{Cl}: 1,00-1,05 \\
\mathrm{p}=0,0830\end{array}$ & $\begin{array}{l}\mathrm{RR}=0,99 \\
\mathrm{Cl}: 0,96-1,01 \\
\mathrm{p}=0,2940\end{array}$ & $\begin{array}{l}\mathrm{RR}=0,93 \\
\mathrm{Cl}: 0,91-0,95 \\
\mathrm{p}<0,001\end{array}$ & $\begin{array}{l}\mathrm{RR}=0,96 \\
\mathrm{Cl}: 0,94-0,99 \\
\mathrm{p}=0,0051\end{array}$ \\
\hline \multirow[t]{2}{*}{ SLH } & 788 & 1225 & 1582 & 1983 & 632 & 2289 \\
\hline & & $\begin{array}{l}\mathrm{RR}=1,55 \\
\mathrm{Cl}: 1,42-1,70 \\
\mathrm{p}<0,001\end{array}$ & $\begin{array}{l}\mathrm{RR}=1,29 \\
\mathrm{Cl}: 1,20-1,39 \\
\mathrm{p}<0,001\end{array}$ & $\begin{array}{l}\mathrm{RR}=1,25 \\
\mathrm{Cl}: 1,17-1,34 \\
\mathrm{p}<0,001\end{array}$ & $\begin{array}{l}\mathrm{RR}=0,32 \\
\mathrm{Cl}: 0,29-0,35 \\
\mathrm{p}<0,001\end{array}$ & $\begin{array}{l}\mathrm{RR}=3,62 \\
\mathrm{Cl}: 3,32-3,96 \\
\mathrm{p}<0,001\end{array}$ \\
\hline
\end{tabular}

SAH — supracervical abdominal hysterectomy; TLH — supracervical laparoscopic hysterectomy; TAH — total abdominal hysterectomy; TLH — total laparoscopic hysterectomy; $\mathrm{Cl}$ - confidence interval; $\mathrm{RR}$ - rate ratio

Table 5. Comparison of the number of total and supracervical hysterectomy procedures with abdominal and laparoscopic approach

\begin{tabular}{|l|l|l|l|l|l|l|}
\hline & $\mathbf{2 0 1 1}$ & $\mathbf{2 0 1 2}$ & $\mathbf{2 0 1 3}$ & $\mathbf{2 0 1 4}$ & $\mathbf{2 0 1 5}$ & $\mathbf{2 0 1 6}$ \\
\hline TAH + SAH & 35364 & 34810 & 34409 & 33744 & 30808 & 28993 \\
\hline TLH + SLH & 850 & 1298 & 1617 & 2100 & 798 & 3091 \\
\hline TLH + SLH \% & $2.35 \%$ & $3.59 \%$ & $4.49 \%$ & $5.85 \%$ & $2.52 \%$ & $9.63 \%$ \\
\hline
\end{tabular}

SAH — supracervical abdominal hysterectomy; TLH — supracervical laparoscopic hysterectomy; TAH — total abdominal hysterectomy; TLH — total laparoscopic hysterectomy; $\mathrm{Cl}$ - confidence interval; $\mathrm{RR}$ - rate ratio

3.32-3.96; $\mathrm{p}<0.001)$. Data regarding SLH is presented in Table 3 and Figure 3.

In the analyzed period, the total number of $\mathrm{VH}$ reached 7,684 . However, a drop by $26.1 \%$ was observed between 2011 and 2016 (1,486 vs 1,098). The annual trend in VH is presented in Figure 4. Additionally, significant increase in minimally invasive procedures was observed. Between 2011 and 2016, the total number of both TLH and SLH increased significantly $(\mathrm{RR}=3.85 ; \mathrm{Cl}$ :
3.57-4.16; $\mathrm{p}<0.001)$ along with a decrease in the number of surgeries with abdominal approach $(R R=0.82$; Cl: $0.81-0.83 ; p<0.001)$. The ratio of minimally invasive surgeries (TLH and SLH) to surgeries performed with the laparotomy approach (TAH and $\mathrm{SAH}$ ) in the subsequent years was $2.3 \%, 3.5 \%, 4.4 \%, 5.8 \%, 2.5 \%$, and $9.6 \%$. A comparison of the surgeries with laparoscopic and abdominal approach is presented in Table 5, 6 and Figure 5. 


\begin{tabular}{|c|c|c|c|c|c|c|}
\hline & 2011 & 2012 & 2013 & 2014 & 2015 & 2016 \\
\hline Total number of women & $19,883,870$ & $19,883,965$ & $19,866,124$ & $19,858,793$ & $19,839,248$ & $19,839,826$ \\
\hline $\mathrm{TLH}+\mathrm{SLH}$ & 850 & 1298 & 1617 & 2100 & 798 & 3269 \\
\hline $\mathrm{TAH}+\mathrm{SAH}$ & 35364 & 34810 & 34409 & 33744 & 30808 & 28993 \\
\hline $\begin{array}{l}\text { TLH + SLH Incidence rate } \\
\text { per } 10.000 \text { women }\end{array}$ & 0.43 & 0.65 & 0.81 & 1.06 & 0.40 & 1.65 \\
\hline $\begin{array}{l}\text { TAH + SAH Incidence rate } \\
\text { per } 10.000 \text { women }\end{array}$ & 17.79 & 17.51 & 17.32 & 16.99 & 15.53 & 14.61 \\
\hline $\mathrm{TLH}+\mathrm{SLH}$ rate ratio with $\mathrm{Cl}$ & & $\begin{array}{l}\mathrm{RR}=1.53 \\
\mathrm{Cl}: 1.40-1.67 \\
\mathrm{p}<0.001\end{array}$ & $\begin{array}{l}\mathrm{RR}=1.90 \\
\mathrm{Cl}: 1.75-2.07 \\
\mathrm{p}<0.001\end{array}$ & $\begin{array}{l}\mathrm{RR}=2.47 \\
\mathrm{Cl}: 2.28-2.68 \\
\mathrm{p}<0.001\end{array}$ & $\begin{array}{l}\mathrm{RR}=0.94 \\
\mathrm{Cl}: 0.85-1.04 \\
\mathrm{p}=0.2167\end{array}$ & $\begin{array}{l}\mathrm{RR}=3.85 \\
\mathrm{Cl}: 3.57-4.16 \\
\mathrm{p}<0.001\end{array}$ \\
\hline $\begin{array}{l}\mathrm{TAH}+\mathrm{SAH} \text { rate ratio with } \\
\mathrm{Cl}\end{array}$ & & $\begin{array}{l}\mathrm{RR}=0.98 \\
\mathrm{Cl}: 0.97-1.00 \\
\mathrm{p}=0.0364\end{array}$ & $\begin{array}{l}\mathrm{RR}=0.97 \\
\mathrm{Cl}: 0.96-0.99 \\
\mathrm{p}=0.0005\end{array}$ & $\begin{array}{l}\mathrm{RR}=0.96 \\
\mathrm{Cl}: 0.94-0.97 \\
\mathrm{p}<0.001\end{array}$ & $\begin{array}{l}\mathrm{RR}=0.87 \\
\mathrm{Cl}: 0.86-0.89 \\
\mathrm{p}<0.001\end{array}$ & $\begin{array}{l}\mathrm{RR}=0.82 \\
\mathrm{Cl}: 0.81-0.83 \\
\mathrm{p}<0.001\end{array}$ \\
\hline
\end{tabular}

$\mathrm{SAH}$ - supracervical abdominal hysterectomy; TLH — supracervical laparoscopic hysterectomy; TAH — total abdominal hysterectomy; TLH — total laparoscopic hysterectomy; $\mathrm{Cl}$ - confidence interval; $\mathrm{RR}$ - rate ratio

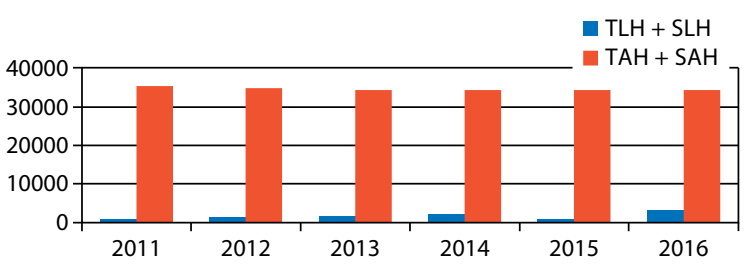

Figure 5. Comparison between the number of total abdominal and laparoscopic hysterectomy procedures; $\mathrm{TAH}$ — total abdominal hysterectomy; TLH — total laparoscopic hysterectomy; SAH — supracervical abdominal hysterectomy; SLH - supracervical laparoscopic hysterectomy

Comparison of the percentage of advanced minimally invasive hysterectomies between countries based on national database reports is presented in Table 7.

\section{DISCUSSION}

Data presented in the study indicate that the number of hysterectomy procedures was decreasing gradually between 2011 and 2016 in Poland. Despite a small increase by $1.7 \%$ in 2016 in comparison to the preceding year, the total drop in those procedures accounted for $11.5 \%$. Changes observed in Poland are similar to those reported in the USA and other European countries $[4,6,9,10]$.

In the present study, a significant reduction in the number of TAH by $24.0 \%$ accompanied by an increase in the number of TLH by $1,193.5 \%$ over the study period suggests a positive change in Polish gynecology. Despite the fact that a laparoscopic procedure is usually longer in comparison to the time needed for the classical approach, benefits for the patients are invaluable. Advantages of laparoscopy include lower intraoperative blood loss, lower demand for analgesics, shorter hospital stay, and shorter recovery period after

\begin{tabular}{|c|c|c|c|c|c|}
\hline & 2010 & 2011 & 2012 & 2013 & 2014 \\
\hline USA & $26.10 \%$ & $32.00 \%$ & $38.50 \%$ & $43.40 \%$ & \\
\hline Poland & & $2.35 \%$ & $3.59 \%$ & $4.49 \%$ & $5.85 \%$ \\
\hline Austria & & & & & $32.00 \%$ \\
\hline
\end{tabular}

the operation compared to a surgery with the abdominal approach [11-13]. Growing experience in laparoscopy among the physicians offers all the advantages of minimally invasive operations also for obese patients and patients with very large fibroids (over 1,000 g) [14-16]. Despite an increase in the percentage of laparoscopic surgeries in relation to abdominal surgeries in Poland from 2.3\% in 2011 to $9.6 \%$ in 2016, still a lot of work and focus on the training of the physicians are needed to come close to the result of $2.0 \%$ in Austria in 2014 or USA 43.4\% in 2013 [17] (Tab. 7).

The initial increase in the number of SLH till 2014 with the subsequent rapid drop by $68.1 \%$ to the lowest number of 632 procedures in 2015 was most likely associated with safety warnings issued by the American Food and Drug Administration regarding the use of morcellation at the end of 2014 despite the lack of any official opinion of Polish scientific societies $[18,19]$. The impact of the recommendations in force in the USA significantly changed the daily practice among both Polish and American practitioners. Retrospective study covering 603 hospitals in US showed an increased rates of open surgery and decreased rate of minimally invasive surgery. In addition significant increased in minor complications as well as major compli- 
cation was observed from $2.7 \%$ to $3.3 \%$ and from $1.9 \%$ to $2.4 \%$ respectively [20]. Advances in the operative techniques resulted in the development of a special intraperitoneal bag to prevent uncontrolled tissue dissemination during morcellation. Additionally, recommendations of the European Society of Gynecological Oncology on fibroid and uterine morcellation resulted in subsequent increase (by $262.2 \%$ ) in the number of SLH in 2016 [21,22]. Reports from the literature showed that careful preoperative counseling further reduces the risk of unexpected malignancies in the uterus and confirmed safety of morcellation in selected group of patients [23].

A drop by $26.1 \%$ in the number of $\mathrm{VH}$ in Poland unfortunately reflects the reduction in the popularity of this procedure in our country. This drop, however, does not change the fact that using proper technique and qualification, this type of hysterectomy is a method of choice for benign gynecological diseases in many gynecological centers. It is especially beneficial considering the complications rate and cost-effectiveness of the procedure. [14, 24-26] Benefits of advanced minimal surgery has been proven in meta-analysis of studies in comparison of total laparoscopic hysterectomy to the total abdominal hysterectomies. Despite a longer operating time in laparoscopic group (weighted mean differences -WMD 22 min; 95\% Cl 5-39 min; $p=0.01$ ), minimally invasive techniques benefit in peri-operative complications (pooled OR 0.19; $95 \% \mathrm{Cl}$ $0.07-0.50$ ), reduced estimated blood loss (WMD $-183 \mathrm{~mL}$; $95 \% \mathrm{Cl}-346 \mathrm{~mL}$ to $-21 \mathrm{~mL} ; \mathrm{p}=0.03)$, as well as shorter hospital stay (WMD -2.5 days; $95 \% \mathrm{Cl}-5.1$ days to 0.01 days; $\mathrm{p}=0.05$ ) and post-operative haematoma formation (pooled OR 0.17; 95\% Cl 0.03-1.01) compared to TAH [27].

Changes observed in numbers of gynecological procedures between 2011-2016 in Poland reflect the changes in gynecological practice in response to new therapeutic possibilities and recommendations issued by international institutions like American Food and Drug Administration and the European Society of Gynecological Oncology Introduction of new pharmacotherapies and intrauterine systems to gynecological treatment is easier than training a specialist to perform safe laparoscopic hysterectomy. A growing number of laparoscopic procedures in our country is of course, a good sign but the gap between Poland and other leading countries highlights the need for a change in our traditional approach. More emphasis should be placed on including minimally invasive hysterectomy in the specialization training. In light of the increasing availability of endoscopic equipment in gynecological centers in our country and a growing number of specialists trained in minimally invasive hysterectomy during numerous operational courses in leading endoscopic centers, the percentage of advanced minimally invasive procedures for hysterectomy will hope- fully increase further in the coming years. This trend could be accelerated if the National Health Fund financially favored minimally invasive surgeries; that strategy would be also beneficial for a Polish taxpayer by reducing absenteeism in a workplace after minimally invasive surgeries; and if more emphasis were put on improving the ability to perform such operations during specialization training of the young physicians.

\section{CONCLUSIONS}

Technological advances, introduction of the intrauterine systems and hormonal therapy, as well as recommendations of various international institutions brought about changes in the methods and frequency of hysterectomy. The laparoscopic approach is steadily gaining popularity due to its benefits for the patients, chief among themlower intraoperative blood loss, and demand for analgesics, shorter hospitalization, and recovery period, as well as benefits for employers such as shorter absence from work. However, the percentage of minimally invasive surgeries in Poland is still low in comparison to other countries.

\section{Acknowledgments}

This research was financed through a statutory subsidy by the Polish Minister of Science and Higher Education as a part of grant STM.C280.18.003.

\section{Limitations of our study}

The limitation of our analysis is to include procedures financed by NFZ. The analysis does not include procedures performed at the patient's expense, as they are not reported to the NFZ.

\section{REFERENCES}

1. Romanek-Piva K, Gałczyński K, Adamiak-Godlewska A, et al. Hysterectomy trends for benign indications over a 15-year period in an academic teaching center in Poland: a retrospective cohort study. Ginekol Pol. 2016; 87(6): 411-416, doi: 10.5603/GP.2016.0017, indexed in Pubmed: 27418216.

2. Finks JF, Osborne NH, Birkmeyer JD. Trends in hospital volume and operative mortality for high-risk surgery. N Engl J Med. 2011; 364(22): $2128-$ 2137, doi: 10.1056/NEJMsa1010705, indexed in Pubmed: 21631325.

3. Streuli I, de Ziegler D, Santulli P, et al. An update on the pharmacological management of endometriosis. Expert Opin Pharmacother. 2013; 14(3): 291-305, doi: 10.1517/14656566.2013.767334, indexed in Pubmed: 23356536.

4. Sambrook AM, Bain C, Parkin DE, et al. A randomised comparison of microwave endometrial ablation with transcervical resection of the endometrium: follow up at a minimum of 10 years. BJOG. 2009; 116(8): 1033-1037, doi: 10.1111/j.1471-0528.2009.02201.x, indexed in Pubmed: 19438487.

5. Gupta J, Kai J, Middleton L, et al. ECLIPSE Trial Collaborative Group. Levonorgestrel intrauterine system versus medical therapy for menorrhagia. N Engl J Med. 2013; 368(2): 128-137, doi: 10.1056/NEJMoa1204724, indexed in Pubmed: 23301731.

6. Rob L, Skapa P, Robova H. Fertility-sparing surgery in patients with cervical cancer. Lancet Oncol. 2011; 12(2): 192-200, doi: 10.1016/S1470-2045(10)70084-X, indexed in Pubmed: 20619737.

7. Driessen SRC, Baden NLM, van Zwet EW, et al. Trends in the implementation of advanced minimally invasive gynecologic surgical procedures in the Netherlands. J Minim Invasive Gynecol. 2015; 22(4): 642-647, doi: 10.1016/j.jmig.2015.01.026, indexed in Pubmed: 25655043. 
8. Mäkinen J, BrummerT, Jalkanen J, et al. Ten years of progress--improved hysterectomy outcomes in Finland 1996-2006: a longitudinal observation study. BMJ Open. 2013; 3(10): e003169, doi: 10.1136/bmjopen-2013-003169, indexed in Pubmed: 24165027.

9. Gupta J, Sinha A, Lumsden MA, et al. Uterine artery embolization for symptomatic uterine fibroids. Cochrane Database of Systematic Reviews. 2014; 12, doi: 10.1002/14651858.cd005073.pub3.

10. Wright JD, Herzog TJ, Tsui J, et al. Nationwide trends in the performance of inpatient hysterectomy in the United States. Obstet Gynecol. 2013; 122(2 Pt 1): 233-241, doi: 10.1097/AOG.0b013e318299a6cf, indexed in Pubmed: 23969789.

11. Balcı O. Comparison of total laparoscopic hysterectomy and abdominal hysterectomy. Turk J Obstet Gynecol. 2014; 11(4): 224-227, doi: 10.4274/tjod.47108, indexed in Pubmed: 28913025.

12. Kürek Eken $M$, İlhan $G$, Temizkan $O$, et al. The impact of abdominal and laparoscopic hysterectomies on women's sexuality and psychological condition. Turk J Obstet Gynecol. 2016; 13(4): 196-202, doi: 10.4274/tjod.71245, indexed in Pubmed: 28913121.

13. Mourits MJE, Bijen CB, Arts HJ, et al. Safety of laparoscopy versus laparotomy in early-stage endometrial cancer: a randomised trial. Lancet Oncol. 2010; 11(8): 763-771, doi: 10.1016/S1470-2045(10)70143-1, indexed in Pubmed: 20638901.

14. Deffieux X, Rochambeau Bde, Chene G, et al. Hysterectomy for benign disease: clinical practice guidelines from the French College of Obstetrics and Gynecology. Eur J Obstet Gynecol Reprod Biol. 2016; 202: 83-91, doi: 10.1016/j.ejogrb.2016.04.006, indexed in Pubmed: 27196085.

15. Schöller D, Taran FA, Wallwiener M, et al. Laparoscopic Supracervical Hysterectomy and Laparoscopic Total Hysterectomy in Patients with Very Large Uteri: a Retrospective Single-Center Experience at a Major University Hospital. Geburtshilfe Frauenheilkd. 2017; 77(3): 251-256, doi: 10.1055/s-0043-102695, indexed in Pubmed: 28392578.

16. Uccella S, Morosi C, Marconi N, et al. Laparoscopic Versus Open Hysterectomy for Benign Disease in Uteri Weighing $>1 \mathrm{~kg}$ : A Retrospective Analysis on 258 Patients. J Minim Invasive Gynecol. 2018; 25(1): 62-69, doi: 10.1016/j.jmig.2017.07.005, indexed in Pubmed: 28711761.

17. Edler KM, Tamussino K, Fülöp G, et al. Rates and Routes of Hysterectomy for Benign Indications in Austria 2002 - 2014. Geburtshilfe Frauenheilkd. 2017; 77(5): 482-486, doi: 10.1055/s-0043-107784, indexed in Pubmed: 28579619.
18. Barron $\mathrm{KI}$, Richard T, Robinson PS, et al. Association of the U.S. Food and Drug Administration Morcellation Warning With Rates of Minimally Invasive Hysterectomy and Myomectomy. Obstet Gynecol. 2015; 126(6): 1174-1180, doi: 10.1097/AOG.0000000000001111, indexed in Pubmed: 26595561.

19. Glaser LM, Friedman J, Tsai S, et al. Laparoscopic myomectomy and morcellation: A review of techniques, outcomes, and practice guidelines. Best Pract Res Clin Obstet Gynaecol. 2018; 46: 99-112, doi: 10.1016/j.bpobgyn.2017.09.012, indexed in Pubmed: 29078975.

20. Multinu F, Casarin J, Hanson KT, et al. Practice Patterns and Complications of Benign Hysterectomy Following the FDA Statement Warning Against the Use of Power Morcellation. JAMA Surg. 2018; 153(6): e180141, doi: 10.1001/jamasurg.2018.0141, indexed in Pubmed: 29641835.

21. Halaska MJ, Haidopoulos D, Guyon F, et al. ESGO Council. European Society of Gynecological Oncology Statement on Fibroid and Uterine Morcellation. Int J Gynecol Cancer. 2017; 27(1): 189-192, doi: 10.1097/IGC.0000000000000911, indexed in Pubmed: 28002210.

22. Leal MA, Piñera A, De Santiago J, et al. Novel Technique for Contained Power Morcellation through Umbilicus with Insufflated Bag. Gynecol Obstet Invest. 2017; 82(2): 205-207, doi: 10.1159/000449157, indexed in Pubmed: 27595411.

23. Rechberger T, Miotła P, Futyma K, et al. Power morcellation for women undergoing laparoscopic supracervical hysterectomy - safety of procedure and clinical experience from 426 cases. Ginekol Pol. 2016; 87(8): 546-551, doi: 10.5603/GP.2016.0042, indexed in Pubmed: 27629127.

24. Aarts J, Nieboer T, Johnson N, et al. Surgical approach to hysterectomy for benign gynaecological disease. Cochrane Database of Systematic Reviews. 2015, doi: 10.1002/14651858.cd003677.pub5.

25. ACOG Committee Opinion No. 444: choosing the route of hysterectomy for benign disease. Obstet Gynecol. 2009; 114(5): 1156-1158, doi: 10.1097/AOG.0b013e3181c33c72, indexed in Pubmed: 20168127.

26. Neis KJ, Zubke W, Römer T, et al. Indications and Route of Hysterectomy for Benign Diseases. Guideline of the DGGG, OEGGG and SGGG (S3 Level, AWMF Registry No.015/070, April 2015). Geburtshilfe Frauenheilkd. 2016; 76(4): 350-364, doi: 10.1055/s-0042-104288, indexed in Pubmed: 27667852.

27. Walsh CA, Walsh SR, Tang TY, et al. Total abdominal hysterectomy versus total laparoscopic hysterectomy for benign disease: a meta-analysis. Eur J Obstet Gynecol Reprod Biol. 2009; 144(1): 3-7, doi: 10.1016/j. ejogrb.2009.01.003, indexed in Pubmed: 19324491. 